\title{
Sympathetic skin responses and psychogenic erections in spinal cord injured men
}

\author{
FJ Courtois ${ }^{1,3}$, P-M Gonnaud ${ }^{2}$, KF Charvier ${ }^{2}$, A Leriche ${ }^{2}$ and DP Raymond ${ }^{3}$ \\ ${ }^{1}$ Université du Québec à Montréal, Montréal, H3C 3P8, Canada; ${ }^{2}$ Hospices civils de Lyon, Saint-Genis-Laval, \\ France; ${ }^{3}$ Institut de réadaptation de Montréal, Montréal H3S 2J4, Canada
}

\begin{abstract}
Sympathetic skin responses (SSR) are a simple procedure to investigate sympathetic activity. More specifically, SSR elicited from median nerve stimulation and recorded from the feet and genitals assess sympathetic activity resulting from thoracic-lumbar (TL) innervation. Since TL innervation is also involved in the mediation of psychogenic erection in spinal cord injured men, this study investigated the relationship between SSR and psychogenic erection in spinal cord injured subjects. The results support a general association between SSR and psychogenic erection and show that subjects who maintain SSR responses in the feet and genitals generally maintain psychogenic erections as well. Inconsistent cases are discussed from a theoretical and clinical perspective and overall results are discussed in terms of their clinical application in the evaluation of sexual function in spinal cord injured men.
\end{abstract}

Keywords: sympathetic skin responses (SSR); penile erection; spinal cord injury; paraplegia

\section{Introduction}

Sympathetic skin responses (SSR) are a non-invasive procedure to record sympathetic activity resulting from sudation. Born from a combination of galvanic skin responses ${ }^{1}$ and microneurography, ${ }^{2}$ SSR has allowed recording of neural activity originating from type $\mathrm{C}$ unmyelinated sympathetic fibers. 3

The earlier GSR procedure was used to measure changes in skin resistance in response to simple stimuli such as an emotional response, a sudden noise or a deep breath. The responses were recorded from surface electrodes which made the procedure easy to investigate underlying sympathetic activity. The stimulation source, however, involved variability among and across subjects which made it slightly unreliable.

Microneurography, in contrast, allowed better control over the stimulation parameters as it involved electrical stimulation of peripheral nerves. The procedure, however, was more invasive than the earlier one as it involved an implant of a recording needle into the skin.

The SSR procedure, developed by Knezevic et al $l^{3}$ and Shanani et $a l^{4}$, combined the advantages of the two earlier ones and involves electrical stimulation of a peripheral nerve and recording from surface electrodes. The technique, used by many authors since, measures changes in skin voltage and recording from surface electrodes placed on the hands ${ }^{5,6}$ and feet ${ }^{5,6}$ and was later adapted to include genital recording as well. ${ }^{7-10}$ The triggering stimulus, originally involving

Correspondence: FJ Courtois median $^{3,6,11-13}$ and tibial ${ }^{14-16}$ nerve stimulation, was also adapted to include suborbital ${ }^{16}$ and dorsal penile nerve ${ }^{9}$ stimulation.

Because of its ease of application and because SSR allowed investigation of sympathetic activity, it triggered a rapid and growing interest in a great variety of neurological conditions. ${ }^{17-27}$ Results have generally shown that SSR is an interesting diagnostic tool to assess dysfunction of the autonomic nervous system, although extensive damage has to be achieved before SSR can reveal a dysfunction. Paradoxally, results have also shown that SSR was poorly correlated with signs of dysautonomia, ${ }^{4,19,25}$ a finding which was interpreted to suggest that SSR may be sensitive to autonomic dysfunction before damage is sufficient to reveal clinical symptoms.

In this study we have used SSR in a slightly different perspective, attempting to explore specific hypotheses related to SSR and psychogenic erectile function reported in spinal cord injured men. ${ }^{28-30}$ As illustrated in Figure 1, SSR was triggered from a supralesional stimulation site and recorded from the hands, feet and genitals. Although the precise transmission of SSR is not completely understood, impulses from the stimulation site are believed to be transmitted to the brain and then to the spinal cord, where connections are made with the sympathetic trunk. ${ }^{10}$ Since sympathetic innervation of the feet and genitals is conveyed by the spinal segments T11 to L2 and since these TL segments are involved in the transmission of psychogenic erection, feet and genital SSR were believed to be consistent with results from psychogenic erectile function. Conversely, hands SSR 
which are conveyed by $\mathrm{T} 2$ to $\mathrm{T} 8$ sympathetic fivers were not expected to be related to psychogenic erectile function and were rather used as a control condition.

\section{Methods}

\section{Subjects}

A total of 54 spinal cord injured men participated in the study. Their age varied between 16 year-old and 54 year-old, with an average of 32 years of age. All lesions were stable for at least 4 months, were located in the spinal cord or cauda equina (CE) and were not associated with signs of polyneuropathy. As illustrated in Table 1, lesion levels varied between the fourth cervical segment (C4) and the third sacral segment (S3) and could be complete (C) or incomplete (I). Subjects were generally without anti-cholinergic medication, except for a few individuals who were treated with anticholinergic agents and for whom treatment was temporarily ceased $24 \mathrm{~h}$ before testing. Medication nevertheless failed to affect SSR recordings since the same number of subjects with and without medication showed normal and abnormal SSR from the hands (five against five subjects).

A group of 15 control subjects also participated in the study to provide normal SSR values. All subjects were men in good health and free of neurological condition. Their age varied between 26 and 65 years with an average of 48 year-old.

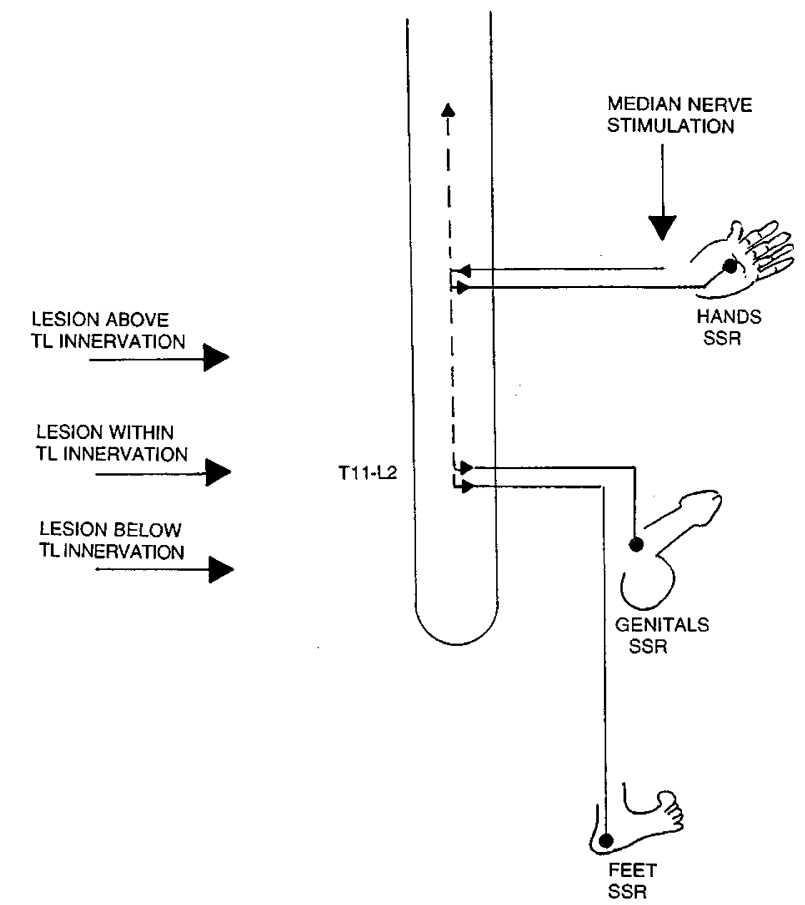

Figure 1 Schematic representation of SSR stimulation and recording sites according to lesion levels. (Adapted from Park et $a l^{10}$ )

\section{Procedure}

The subjects were tested in a semi-darkened room maintained at a constant ambient temperature of $27^{\circ} \mathrm{C}$ or $28^{\circ} \mathrm{C}$ and restricted from surrounding noise. During testing, the subjects were lying supine on an examination table, eyes closed and relaxed. Feet temperature was controlled and warmed with a hot bottle and blanket if cooled.

SSR was recorded according to traditional procedure using surface electrodes covered with conducting paste and attached to the palm and dorsum of the hands and sole and dorsum of the foot. Although not routinely used, genital recordings were achieved to explore possible relationship between SSR and psychogenic erectile function in spinal cord injured men. Recording electrodes were placed dorsal to the base of the penis and on the pubic area. In all cases, the ground electrode was attached to the iliac crest.

Electrical stimulation consisted of single square pulses of $0.2 \mathrm{~s}$ to $0.5 \mathrm{~s}$ duration and $20 \mathrm{mV}$ intensity, delivered from a Sapphire Medilec equipment. Stimulation was supralesional and applied to the left median nerve on the wrist for the majority of the subjects, except for those whose lesion was located directly on, or above, median nerve innervation. For these subjects stimulation was applied respectively to the left radial nerve or left supraorbital nerve. Five to six trials, separated by a $30 \mathrm{~s}$ interval to avoid habituation, were performed on each subject.

The data selected for SSR recording consisted of the latency of the response, rather than the amplitude which is highly variable and unvalid. 5,27,34 Latency was defined as the time elapsed between the triggering stimulus, which automatically started the recording, and any positive or negative change from baseline. Normal latency was defined according to the average value recorded from the control subjects plus two standard deviations to allow normal variation in the response.

Sexual function was assessed on a separate session. For this test, the subjects were lying comfortably on a bed and were provided with intimacy to watch an erotic movie. They were asked not to masturbate in order to avoid additional peripheral stimulation during psychogenic stimulation. Erection was recorded with the Rigiscan device (Dacomed) provided with a loop placed at the base of the penis and recording changes in penile circumference and rigidity. (The tip loop was not used as it interfered with masturbation). Changes in penile circumference were recorded as an indication of functional TL innervation (rigidity measure was not considered since it involves additional muscular activity, itself involving sacral in addition to the investigated TL innervation). Positive responses to psychogenic stimulation were defined as changes in penile circumference greater than $1 \mathrm{~cm}$ to be considered beyond experimental artefact. 
Table 1

\begin{tabular}{|c|c|c|c|c|c|c|c|c|c|c|c|c|}
\hline \multirow{2}{*}{ Lesion level } & \multirow[b]{2}{*}{ Age } & \multicolumn{4}{|c|}{$N V=1.37+.16$} & \multicolumn{3}{|c|}{$N V=1.87+.20$} & \multicolumn{4}{|c|}{$N V=1.36+.22$} \\
\hline & & Right hand & & Left hand & & Right foot & & Left foot & & Genitals & & $P E$ \\
\hline \multicolumn{13}{|l|}{ Above TL } \\
\hline C4-I & 37 & 1.62 & $\mathrm{AL}$ & 1.54 & NL & 1.69 & NL & 2.34 & $\mathrm{AL}$ & 1.25 & NL & $\mathrm{P}$ \\
\hline C6-I & 22 & Abs & $\mathrm{AB}$ & Abs & $\mathrm{AB}$ & Abs & $\mathrm{AB}$ & Abs & $\mathrm{AB}$ & Abs & $\mathrm{AB}$ & $\mathrm{N}$ \\
\hline C6-C & 32 & 1.59 & $\mathrm{AL}$ & 1.59 & AL & Abs & $\mathrm{AB}$ & Abs & $\mathrm{AB}$ & Abs & $\mathrm{AB}$ & $\mathrm{N}$ \\
\hline C6-C & 19 & 1.52 & $\mathrm{AL}$ & 1.53 & $\mathrm{AL}$ & 2.50 & AL & 2.31 & $\mathrm{AL}$ & 1.22 & NL & $\mathrm{N}$ \\
\hline C7-I & 28 & 1.42 & NL & 1.40 & NL & 2.29 & $\mathrm{AL}$ & 2.14 & $\mathrm{AL}$ & Abs & $\mathrm{AB}$ & $\mathrm{N}$ \\
\hline T1-I & 38 & 1.50 & NL & 1.22 & NL & 1.87 & NL & 1.68 & NL & 1.51 & NL & $\mathrm{N}$ \\
\hline $\mathrm{T} 2-\mathrm{C}$ & 24 & 1.73 & AL & Abs & $\mathrm{AB}$ & Abs & $\mathrm{AB}$ & Abs & $\mathrm{AB}$ & Abs & $\mathrm{AB}$ & $\mathrm{N}$ \\
\hline $\mathrm{T} 4-\mathrm{C}$ & 27 & 1.47 & NL & 1.42 & NL & Abs & $\mathrm{AB}$ & Abs & $\mathrm{AB}$ & Abs & $\mathrm{AB}$ & $\mathrm{N}$ \\
\hline $\mathrm{T} 4-\mathrm{C}$ & 24 & 1.44 & NL & - & - & Abs & $\mathrm{AB}$ & Abs & $\mathrm{AB}$ & Abs & $\mathrm{AB}$ & $\mathrm{N}$ \\
\hline $\mathrm{T} 4-1$ & 32 & Abs & $\mathrm{AB}$ & Abs & $\mathrm{AB}$ & Abs & $\mathrm{AB}$ & Abs & $\mathrm{AB}$ & Abs & $\mathrm{AB}$ & $\mathrm{N}$ \\
\hline T4-1 & 17 & Abs & $\mathrm{AB}$ & Abs & $\mathrm{AB}$ & Abs & $\mathrm{AB}$ & Abs & $\mathrm{AB}$ & Abs & $\mathrm{AB}$ & $\mathrm{N}$ \\
\hline T4-C & 31 & 1.56 & $\mathrm{AL}$ & 1.53 & NL & Abs & $\mathrm{AB}$ & Abs & $\mathrm{AB}$ & Abs & $\mathrm{AB}$ & $\mathrm{N}$ \\
\hline T4-C & 23 & 1.24 & NL & - & - & Abs & $\mathrm{AB}$ & Abs & $\mathrm{AB}$ & Abs & $\mathrm{AB}$ & $\mathrm{P}$ \\
\hline T5-I & 23 & Abs & $\mathrm{AB}$ & 2.77 & $\mathrm{AL}$ & Abs & $\mathrm{AB}$ & Abs & $\mathrm{AB}$ & Abs & $\mathrm{AB}$ & $\mathrm{N}$ \\
\hline T5-C & 24 & 1.58 & $\mathrm{AL}$ & 1.52 & NL & Abs & $\mathrm{AB}$ & Abs & $\mathrm{AB}$ & Abs & AB & $\mathrm{N}$ \\
\hline T5-C & 33 & 1.53 & NL & 1.33 & NL & Abs & $\mathrm{AB}$ & Abs & $\mathrm{AB}$ & Abs & $\mathrm{AB}$ & $\mathrm{N}$ \\
\hline T5-I & 30 & 1.44 & NL & - & - & Abs & $\mathrm{AB}$ & Abs & $\mathrm{AB}$ & Abs & $\mathrm{AB}$ & $\mathrm{N}$ \\
\hline T5-C & 24 & Abs & $\mathrm{AB}$ & Abs & $\mathrm{AB}$ & Abs & $\mathrm{AB}$ & Abs & $\mathrm{AB}$ & Abs & $\mathrm{AB}$ & $\mathrm{P}$ \\
\hline T6-I & 43 & 1.38 & NL & 1.30 & NL & Abs & $\mathrm{AB}$ & Abs & $\mathrm{AB}$ & Abs & $\mathrm{AB}$ & $\mathrm{N}$ \\
\hline T6-C & 24 & 1.42 & NL & - & - & Abs & $\mathrm{AB}$ & 1.99 & $\mathrm{AL}$ & 1.65 & $\mathrm{AL}$ & $\mathrm{N}$ \\
\hline T7-C & 21 & 2.26 & $\mathrm{AL}$ & 1.73 & $\mathrm{AL}$ & Abs & $\mathrm{AB}$ & Abs & $\mathrm{AB}$ & Abs & AB & $\mathrm{N}$ \\
\hline T7-C & 16 & Abs & $\mathrm{AB}$ & Abs & $\mathrm{AB}$ & Abs & $\mathrm{AB}$ & Abs & $\mathrm{AB}$ & Abs & $\mathrm{AB}$ & $\mathrm{N}$ \\
\hline T7-I & 34 & 1.84 & $\mathrm{AL}$ & 1.91 & $\mathrm{AL}$ & Abs & $\mathrm{AB}$ & Abs & $\mathrm{AB}$ & Abs & $\mathrm{AB}$ & $\mathrm{P}$ \\
\hline T7-C & 23 & 1.30 & NL & - & - & 1.84 & NL & 1.78 & NL & 1.33 & NL & $\mathrm{N}$ \\
\hline T7-C & 26 & 1.21 & NL & 1.22 & NL & Abs & $\mathrm{AB}$ & Abs & $\mathrm{AB}$ & Abs & $\mathrm{AB}$ & $\mathrm{N}$ \\
\hline T7-I & 21 & 1.52 & NL & Abs & $\mathrm{AB}$ & Abs & $\mathrm{AB}$ & Abs & $\mathrm{AB}$ & Abs & $\mathrm{AB}$ & $\mathrm{N}$ \\
\hline T8-I & 19 & 1.74 & $\mathrm{AL}$ & - & - & Abs & $\mathrm{AB}$ & 2.32 & $\mathrm{AL}$ & 1.56 & NL & $\mathrm{N}$ \\
\hline T9-C & 28 & 1.57 & $\mathrm{AL}$ & 1.60 & $\mathrm{AL}$ & Abs & $\mathrm{AB}$ & Abs & $\mathrm{AB}$ & 1.51 & NL & $\mathrm{N}$ \\
\hline T9-I & 26 & 1.50 & NL & - & - & 2.30 & $\mathrm{AL}$ & - & - & 1.42 & NL & $\mathrm{N}$ \\
\hline T10-C & 28 & 1.33 & $\mathrm{NL}$ & 1.25 & NL & 2.27 & $\mathrm{AL}$ & 2.20 & $\mathrm{AL}$ & 1.51 & NL & $\mathrm{N}$ \\
\hline \multicolumn{13}{|l|}{$T L$} \\
\hline $\mathrm{T} 11$ & 32 & 1.34 & NL & - & - & Abs & $\mathrm{AB}$ & Abs & $\mathrm{AB}$ & Abs & $\mathrm{AB}$ & $\mathrm{N}$ \\
\hline L1-C & 28 & 1.31 & NL & 1.34 & NL & 1.65 & NL & 1.65 & NL & 1.21 & NL & $\mathrm{P}$ \\
\hline L1-I & 46 & 1.26 & NL & - & - & Abs & $\mathrm{AB}$ & 2.25 & $\mathrm{AL}$ & 2.79 & $\mathrm{AL}$ & $\mathrm{N}$ \\
\hline L1-I & 45 & 1.12 & NL & - & - & 2.43 & $\mathrm{AL}$ & 2.26 & $\mathrm{AL}$ & - & - & $\mathrm{P}$ \\
\hline L1-I & 38 & 1.27 & NL & 1.29 & NL & 2.08 & $\mathrm{AL}$ & 2.08 & $\mathrm{AL}$ & 1.96 & $\mathrm{AL}$ & $\mathrm{P}$ \\
\hline L2-I & 38 & 1.31 & NL & - & - & 1.81 & NL & 1.75 & NL & 1.31 & NL & $\mathrm{P}$ \\
\hline L2-I & 26 & 1.80 & $\mathrm{AL}$ & 1.83 & $\mathrm{AL}$ & 2.12 & $\mathrm{AL}$ & 1.94 & NL & 1.11 & $\mathrm{NL}$ & $\mathrm{P}$ \\
\hline \multicolumn{13}{|l|}{ Below TL } \\
\hline L3-C & 42 & 1.36 & NL & 1.34 & NL & 1.89 & NL & 1.93 & NL & 1.49 & NL & $\mathrm{N}$ \\
\hline L4-I & 29 & 1.32 & NL & - & - & 2.83 & AL & Abs & $\mathrm{AB}$ & 1.14 & NL & $\mathrm{P}$ \\
\hline L5-I & 33 & 1.11 & NL & 1.08 & NL & 1.81 & NL & 1.80 & NL & 1.32 & NL & $\mathrm{P}$ \\
\hline L5-I & 39 & 1.33 & NL & - & - & 2.28 & $\mathrm{AL}$ & 1.92 & NL & 1.39 & $\mathrm{NL}$ & $\mathrm{P}$ \\
\hline L5-I & 25 & 1.42 & NL & 1.36 & NL & 1.77 & NL & 1.67 & NL & 1.27 & NL & $\mathrm{N}$ \\
\hline S1-I & 32 & 1.41 & NL & - & - & 1.98 & NL & 2.05 & NL & 1.37 & NL & $\mathrm{P}$ \\
\hline S1-I & 45 & 1.35 & NL & - & - & 2.18 & $\mathrm{AL}$ & 2.35 & NL & 1.50 & $\mathrm{NL}$ & $\mathrm{P}$ \\
\hline S1-I & 45 & 1.29 & NL & - & - & 1.68 & NL & 1.80 & NL & 2.38 & $\mathrm{AL}$ & $\mathrm{P}$ \\
\hline S2-I & 49 & 1.61 & $\mathrm{AL}$ & - & - & 1.80 & NL & 1.99 & $\mathrm{AL}$ & 1.31 & NL & $\mathrm{P}$ \\
\hline S2-I & 23 & 1.43 & NL & 1.33 & NL & 1.93 & NL & - & - & 1.27 & $\mathrm{NL}$ & $\mathrm{P}$ \\
\hline S3-I & 46 & 1.32 & NL & - & - & 2.06 & NL & 2.29 & $\mathrm{AL}$ & 1.23 & NL & $\mathrm{N}$ \\
\hline S3-I & 34 & 1.26 & NL & 1.28 & NL & 1.58 & NL & 1.63 & NL & 1.16 & NL & $\mathrm{P}$ \\
\hline S3-I & 54 & 1.38 & NL & - & - & 2.18 & $\mathrm{AL}$ & 2.05 & NL & 2.18 & $\mathrm{AL}$ & $\mathrm{P}$ \\
\hline CE(L1)-I & 54 & 1.28 & NL & - & - & 2.03 & NL & 2.06 & NL & 1.25 & NL & $\mathrm{P}$ \\
\hline CE(L1)-I & 43 & 1.24 & NL & 1.29 & NL & Abs & $\mathrm{AB}$ & Abs & $\mathrm{AB}$ & 1.70 & $\mathrm{AL}$ & $\mathrm{N}$ \\
\hline $\mathrm{CE}(\mathrm{L} 2)-\mathrm{C}$ & 41 & 1.51 & NL & - & - & 2.38 & $\mathrm{AL}$ & 2.24 & $\mathrm{AL}$ & 1.31 & NL & $\mathrm{P}$ \\
\hline CE(L2)-I & 52 & 1.61 & $\mathrm{AL}$ & - & - & 1.97 & NL & 1.91 & NL & 1.90 & $\mathrm{AL}$ & $\mathrm{P}$ \\
\hline
\end{tabular}

$\mathrm{NV}=$ normal value, $\mathrm{C}=$ complete injury, $\mathrm{I}=$ incomplete injury, $\mathrm{CE}=$ cauda equina, $\mathrm{AL}=$ abnormal latency, $\mathrm{AB}=\mathrm{absent}$ latency, $\mathrm{NL}=$ normal latency, $\mathrm{PE}=$ psychogenic erection, $\mathrm{N}=$ negative, $\mathrm{P}=$ positive, $(-)=$ missing data. 


\section{Results}

The results for each subject are presented in Table 1 . Each SSR was followed by a code comparing the result to normal values and indicating whether the latency was normal (NL), abnormal (AL) or absent (AB). Normal values (NV) were defined as the mean latency obtained by the control subjects plus two standard deviations, that is, $1.37 \mathrm{~s}+(2)(0.08 \mathrm{~s})$ for hands SSR, $1.87 \mathrm{~s}+(2)(0.10 \mathrm{~s})$ for feet SSR and $1.36 \mathrm{~s}+(2)(0.11 \mathrm{~s})$ for genitals SSR.

The overall results were also reorganized in Figures $2-4$ to allow tentative interpretation of SSR assessment and psychogenic erectile function based on lesion levels. Figure 2 thereby illustrates the combination of feet SSR and psychogenic erection according to different lesion types, while Figure 3 illustrates the combination of genital SSR and psychogenic erection and Figure 4 the combination of hands SSR and psychogenic erection.

Figure 2 shows that within the groups of lesions, SSR was generally absent in subjects with lesions

Right foot

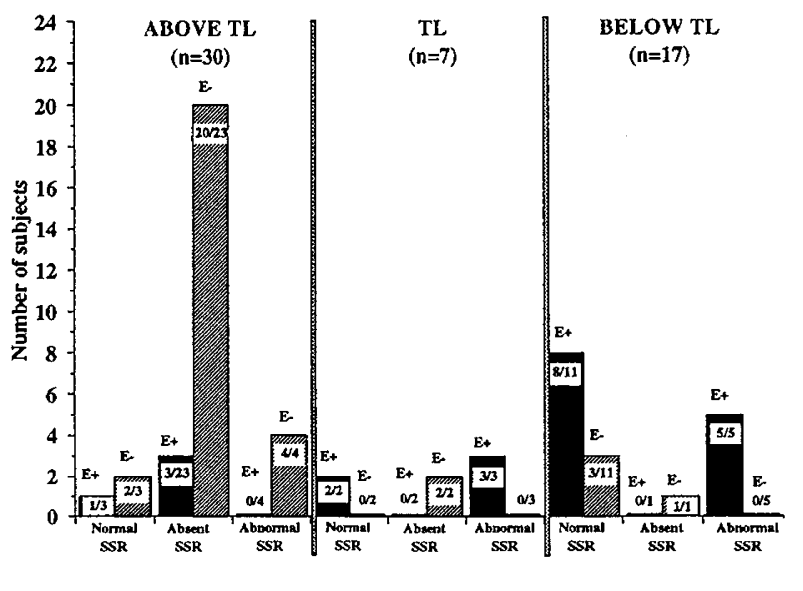

Left foot

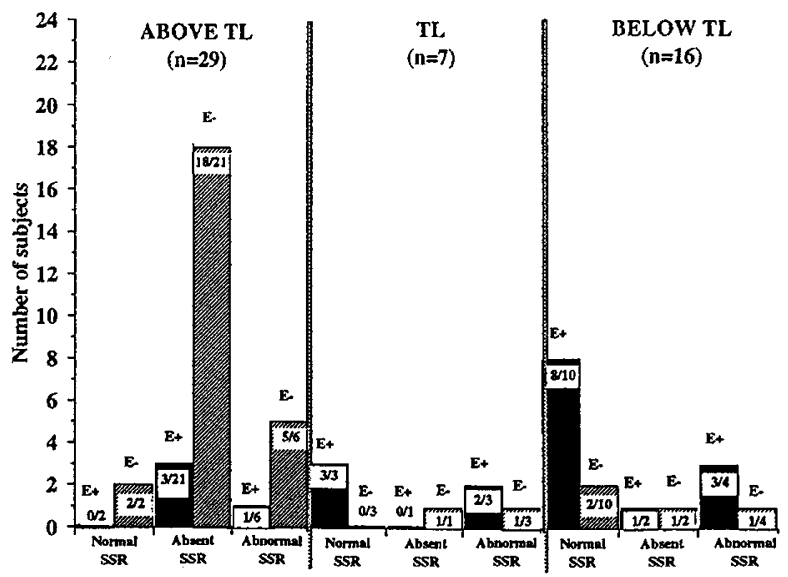

Figure 2 Relationship between feet SSR and presence $\left(\mathrm{E}^{+}\right)$ and absence $\left(\mathrm{E}^{-}\right)$of psychogenic erection according to lesion levels

\section{Genitals}

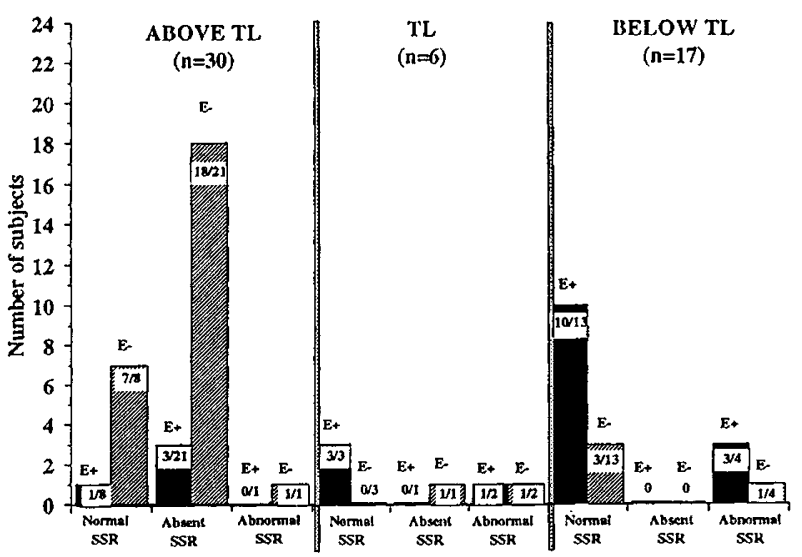

Figure 3 Relationship between genital SSR and presence $\left(\mathrm{E}^{+}\right)$and absence $\left(\mathrm{E}^{-}\right)$of psychogenic erection according to lesion levels

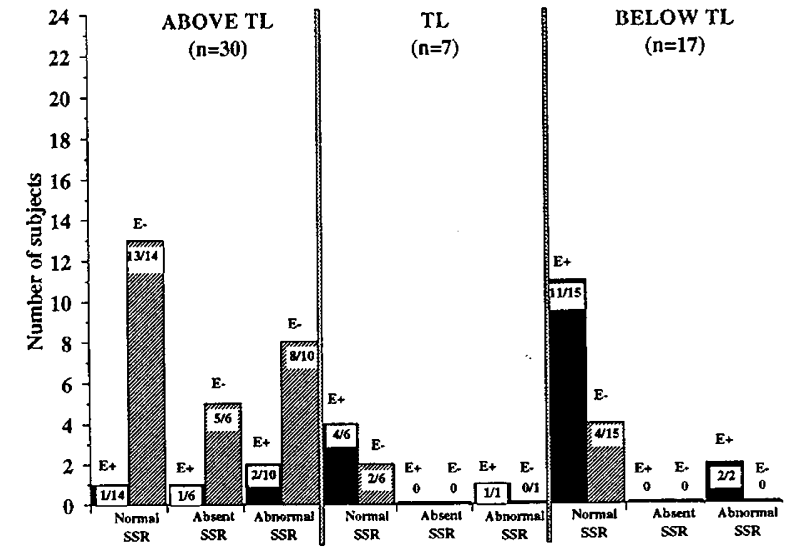

Left hand

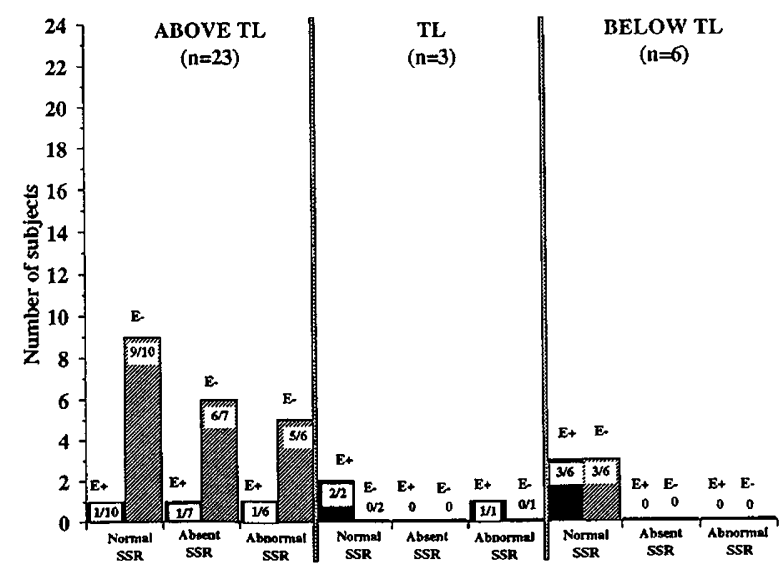

Figure 4 Relationship between hand SSR and presence $\left(\mathrm{E}^{+}\right)$ and absence $\left(\mathrm{E}^{-}\right)$of psychogenic erection according to lesion levels 
above TL innervation. As such, it was absent in 23 subjects and delayed in four subjects out of 30 in the left foot, and absent in 21 subjects and delayed in six out of 29 in the right foot. Overall, SSR was therefore absent or abnormal in 27 out of 29 and 30 subjects when TL transmission was partially or completely interrupted by higher lesions.

Similar to the above, psychogenic erection was generally impaired in subjects with lesions above TL innervation. As such, psychogenic erection was absent in 26 out of 30 subjects $\left(2 \mathrm{E}^{+}+20 \mathrm{E}^{+}+4 \mathrm{E}^{+}\right)$. When both SSR and psychogenic erection results were considered together, subjects with lesions above TL innervation and showing absent SSR generally showed absent psychogenic erection. Indeed, 20 out of 23 subjects with absent SSR lacked psychogenic erection and only two subjects with absent SSR and one with abnormal SSR exhibited psychogenic erections.

The findings from subjects with lesions below TL innervation showed the reverse tendency. Overall, these subjects tended to show normal or delayed SSR in 16 out of 17 cases ( 11 absent +5 abnormal) in the right foot and in 14 out of 16 cases $(10+4)$ in the left foot. Psychogenic erection was also found positive in 12 out of 16 subjects $\left(8 \mathrm{E}^{+}+1 \mathrm{E}^{+}+3 \mathrm{E}^{+}\right)$. Combining SSR results and psychogenic erectile function revealed that the majority of subjects exhibiting normal SSR also exhibited psychogenic erection (eight out of 11 subjects). Very few subjects, in contrast, exhibited psychogenic erections when SSR was absent (three out of 11 cases).

The intermediate group of subjects with lesions located within the TL segments were associated with fewer and more variable responses, which was to be expected given that these lesions can interrupt or spare TL mediation depending upon their exact location with respect to TL segments.

Figure 3 illustrates the findings from genitals SSR and psychogenic erection, again considering different lesion levels. Consistent with the previous findings on feet SSR, subjects with lesions above TL innervation generally showed absent or abnormal genitals SSR. Similarly, absent genitals SSR was generally associated with absent psychogenic erection (18 out of 21 ), except for a few subjects (three out of 21).

In contrast to the above group of lesions, all subjects with lesions below TL innervation showed normal or delayed SSR from the genitals, with no subject exhibiting absent SSR. Subjects also showed psychogenic erections in the majority of cases (15 out of 19 subjects). Combining SSR results and psychogenic erection revealed that normal genitals SSR was associated with psychogenic erections in 12 out of 15 subjects with lesions below TL innervation.

Figure 4 illustrates the results for hands SSR. Contrary to the findings on feet and genitals SSR, hands SSR were not expected to be related to psychogenic erectile function in spinal cord injured men. Since SSR transmission in the hands is not conveyed by the TL pathway involved in sexual function, results from hands SSR were not expected to be related to psychogenic erectile function and were rather used as a control condition during the experiment.

As expected, subjects with lesions above TL innervation generally showed normal (14 out of 30 subjects) or delayed (10 out of 30 subjects) SSR, with very few subjects exhibiting psychogenic erections $\left(1 \mathrm{E}^{+}+1 \mathrm{E}^{+}+2 \mathrm{E}^{+}\right)$. Combining SSR results and psychogenic erection thereby revealed only one subject with normal SSR exhibiting psychogenic erections.

Subjects with lesions below TL innervation also failed to reveal a relationship between hands SSR and psychogenic erection. Overall, however, these subjects were expected to show both types of responses since the connections necessary for each type of response were maintained. As expected, all subjects with lesions below TL innervation showed normal or delayed SSR, and no subject exhibited absent SSR. Similarly, the majority of subjects $\left(11 \mathrm{E}^{+}+2 \mathrm{E}^{+}\right)$exhibited psychogenic erections with only a few lacking responses during testing.

\section{Discussion}

This study was carried out to investigate the relationship between SSR and psychogenic erection. Because SSR from the feet and genitals are transmitted via the TL pathway ${ }^{9,10}$ and because the TL pathway is also involved in the transmission of psychogenic erection, ${ }^{28,30}$ it was believed that SSR results from the feet and genitals would reflect the integrity of the TL pathway and would therefore be associated (in the same subject) with maintenance of psychogenic erections. The study also considered lesion levels, since higher lesions were expected to interrupt the necessary connections for SSR transmission in the feet and genitals, and to interrupt the necessary connections for the transmission of psychogenic erections. Conversely, subjects with lesions below TL innervation were expected to maintain the necessary connections for SSR transmission in the feet and genitals, and were expected to maintain the necessary connections for psychogenic erections.

The data generally supported these theoretical perspectives and showed that subjects with lesions above TL innervation exhibited, for the most part, absent - or at least delayed SSR - in the feet and genitals. The majority of these subjects also lacked psychogenic erection, and the combination of SSR and psychogenic erections revealed that subjects with lesions above TL innervation who lacked SSR responses, tended to lack psychogenic erection as well. As far as lower lesions were concerned, all subjects showed some SSR responses in the feet and genitals - although some responses could be delayed and the majority of subjects showed positive psychogenic erections. 
Despite these results supporting the theorectical neural perspectives, it was interesting to note a few subjects, within the group of lesions above TL innervation, who exhibited absent SSR but who nevertheless exhibited psychogenic erections. While these unexpected findings could have been attributed to partial lesions, a glance at Table 1 revealed that two such subjects actually suffered from complete spinal lesions (23-year-old T4-C subject and 24 year-old T5-C subject). Although speculative, given the small number of subjects showing this pattern, the results may suggest that psychogenic erection can use alternative routes within the paravertebral sympathetic chain to trigger penile responses. A candidate for this alternative route could be the vagus nerve which has been suggested by Whipple $e a^{31}$ to convey sexual impulses in spinal cord injured women suffering from complete lesions.

A few subjects within the group of lesions below TL innervation also showed results inconsistent with the theoretical perspective and exhibited normal SSR responses but absent psychogenic erection. This finding may possibly be attributed to the laboratory condition which may not be sufficiently arousing (with the provided movie) to promote positive erections in subjects, nevertheless capable of sympathetic SSR transmission. This interpretation, however, would require further investigation with other sources of stimulation to be confirmed.

Results from hands SSR further confirmed the theoretical perspective and showed a general lack of relationship between hands SSR and psychogenic erectile function. Therefore, despite the few cases of inconsistent findings, the results generally suggest a relationship between SSR and psychogenic erectile function in spinal cord injured men. This finding may be of clinical interest since our previous study, ${ }^{30}$ and that of others, ${ }^{32}$ have indicated that spinal cord injured men tend to underestimate their erectile potential, especially that related to psychogenic function. Our previous results had shown that erectile responses were more often present in plethysmographic recordings compared to subjective reports. If feet and genitals SSR could be used to assess the integrity of the sympathetic pathway, it could provide some indirect assessment of psychogenic erection in spinal cord injured men and could therefore be useful to compensate for unreliable subjective reports. SSR assessment could also accompany clinical evaluations which can only rely on few reflexes to test TL innervation, which reflexes especially the lower abdominal and cremasteric reflexes can give unreliable results. Furthermore, SSR assessment could accompany other physiological investigations which tend to explore somatic, rather than autonomic, innervation. Finally, it could accompany NPT assessment which, in our setting, has been found to lead to negative results in paraplegic men who nevertheless showed diurnal psychogenic erections. $^{33}$

While few studies have investigated SSR in spinal cord injured men, ${ }^{34-36}$ they have been used to investigate general autonomic function as opposed to remaining sexual function. Their results have generally shown that SSR could be triggered by supralesional stimulation, involving the median nerve ${ }^{34}$ or the supraorbital nerve, ${ }^{36}$ and sublesional stimulation, involving the tibial $^{34}$ nerve, to elicit responses. Sublesional stimulation was also found to appear in natural conditions of bladder contractions ${ }^{35}$ which increase intravesical pressure and lead to positive SSR responses. The present findings therefore further documents the use of SSR in spinal cord injured men to indirectly investigate remaining sexual function, in addition to general autonomic function and specific bladder function.

\section{Acknowledgements}

The authors with to thank $\mathrm{Mr}$ Serge Raymond for his participation in the research project. This research was funded by FRSQ (Fonds de la Recherche en Santé du Québec) and by the Foundation André Sénécal (Québec, Canada) for research on spinal cord injury.

\section{References}

1 Yokota T, Takahashi T, Kondon M, Fujimori B. Studies on the diphasic wave form of the galvanic skin reflex. Electroencephalog Clin Neurophiol 1959; 11: 687-696.

2 Fagius J, Wallin BG. Sympathetic reflexe latencies and conduction velocities in patients with polyneuropathy. $J$ Neurol Sci 1980; 47: $441-461$.

3 Knezevic W, Bajada S. Peripheral autonomic surface potential. A quantitative technique for recording sympathetic conduction. $J$ Neurol Sci 1985; 67: 239-251. 47: 449-461.

4 Shahani BT, Halperin JJ, Boulu P, Cohen J. Sympathetic skin response: a method of assessing unmyelinated axon dysfunction in peripheral neuropathies. J Neurol Neurosurg Psychiat 1984; 47: $536-542$

5 Amarenco G, Desterbecq E, Kerdraon J, Perrigot M. Apport des potentiels évoqués cutanés sympathiques dans l'expertise des troubles neuropérinéaux. À propos des 973 observations. Ann Readaptation Med Phys 1995; 38: 157-160.

6 Elie B, Guiheneuc P. Sympathetic skin response: normal results in different experimental conditions. Electroencephalog Clin Neurophysiol 1990; 76: $258-267$.

7 Amarenco G, Kerdraon J. Perineal electrophysiological studies in erectile dysfunctions. Study of 423 cases. Ann Med Int Paris 1993; 144: 383 - 388 .

8 Daffertshofer M et al. Int J Impot Res 1994; 6: 213 - 225.

9 Ertekin C et al. Skin potentials (SP) recorded from the extremities and genital regions in normal and impotent subjects. Acta Neurol Scand 1987; 76: $28-36$.

10 Park YC et al. Sympathetic skin response: a new test diagnose ejaculatory dysfunction. J Urol 1988; 139: 539-541.

11 Baba M, Watahiki Y, Matsunaga M, Takebe K. Sympathetic skin response in healthy man. Electromyogr Clin Neurophysiol 1988; 28: $277-283$

12 Drory VE, Korczyn AD. Sympathetic skin response: Age effect. Neurology 1993; 43: $1818-1820$.

13 Rossini PM, Opsomer RJ, Boccasena P. Sudomotor skin response following nerve and brain stimulation. Electromyogr Clin Neurophysiol 1993; 89: $442-446$.

14 Chong-Tae K, Sae-il C. Sympathetic skin response recorded by 4 channel recording system. Yonsei Med J 1994; 35: 149-154.

15 Tzeng SS, Wu ZA, Chu FL. The latencies of sympathetic skin responses. Eur Neurol 1993; 33: 65-68. 
16 Uncini A, Pullman SL, Lovelace RE, Gambi D. The sympathetic skin response: normal values, elucidation of afferent components and application limits. J Neurol Sci 1988; 87: 299-306.

17 Andary MT, Stolov WC, Nutter PB. Sympathetic skin response in fifth lumbar and first sacral radiculopathies. Electromyogr Clin Neurophysiol 1993; 33: $91-99$.

18 Caminero A, Perz-Jiminez A, Barreiro P, Ferrer T. Sympathetic skin response: correlation with autonomic and somatic involvement in multiple sclerosis. Electromyogr Clin Neurophysiol 1995 35: $457-462$

19 Dettmer SC, Fatepour D, Faust H, Jerusalem F. Sympathetic skin response abnormalities in amyotrophic lateral sclerosis. Muscle and Nerve 1993; 16: $930-934$.

20 Drory VE, Korczyn AD. The sympathetic skin response in reflex sympathetic dystrophy. J Neurol Sci 1995; 128: 92 -95. 3.

21 Elie B, Louboutin J. Sympathetic skin response (SSR) is abnormal in multiple sclerosis. Muscle and Nerve 1995; 18: $185-189$

22 Ertekin C, Almis S, Ertekin N. Sympathetic skin potentials and bulbocavernosus reflex in patients with chronic alcoholism and impotence. Eur Neurol 1990; 30: 334-337.

23 Miralles R, Espedaier JM, Navrro X, Rubies-Prat J. Autonomic neuropathy in chronic alcoholism: evaluation of cardiovascular, pupillary and sympathetic skin responses. Eur Neurol 1995; 35: $287-292$.

24 Ropper A, Wijdicks E, Shahani B. Electrodiagnostic abnormalities in 113 consecutive patients with Guillan-Barre Syndrome. Arch Neurol 1990; 47: 881 - 887.

25 Taly AB, Muthane UB. Involvement of peripheral nervous system in juvenile Parkinson's disease. Acta Neurol Scand 1992; 85: $272-275$

26 Yokota T, Hayashi M, Tanabe H, Tsukagoshi H. Sympathetic skin response in patients with cerebellar degeneration. Arch Neurol 1993; 50: $422-427$
27 Zgur T et al. Autonomic system dysfunction in moderate diabetic polyneuropathy assessed by sympathetic skin response and Valsalva index. Electromyogr Clin Neurophysiol 1993; 33: $433-$ 439.

28 Chapelle PA, Durand J, Lacert P. Penile erection following complete spinal cord injury in man. Br J Urol 1980; 52: 216-219.

29 Comarr AE. Sexual function among patients with spinal cord injury. Urol Inv 1970; 25: $134-168$

30 Courtois F, Charvier K, Leriche A, Raymond D. Sexual function in spinal cord injury men. I. Assessing sexual capability. Paraplegia 1993; 31: $771-784$.

31 Whipple B, Gerdes CA, Komisaruk BR. Sexual response to selfstimulation in women with complete spinal cord injury. $J$ of Sex Resch 1996; 33: $231-240$.

32 Kennedy S, Over R. Psychophysiological assessment of male sexual arousal following spinal cord injury. Arch Sex Behav 1990; 19: $15-27$.

33 Courtois $\mathrm{F}$ et al. Faux diagnostic d'impuissance chez l'homme blessé médullaire. 9e congrès de la SOFMERR, Nantes, France, Septembre 1994.

34 Hanson P et al. Sympathetic skin response in spinal cord injured patients: preliminary report. Electromyogr Clin Neurophysiol 1992; 32: 555 - 55.

35 Previnaire JG, Soler JM, Hanson P. Skin potential recordings during cystometry in spinal cord injured patients. Paraplegia 1993; 31: 13-21.

36 Yokota $\mathrm{T}$ et al. Sympathetic skin response in patients with multiple sclerosis compared with patients with spinal cord transection and normal controls. Brain 1991; 114: 1381 - 1394

37 Arunodaya G, Taly A. Sympathetic skin response: a decade later. J Neurol Sci 1995; 129: 81 - 89. 